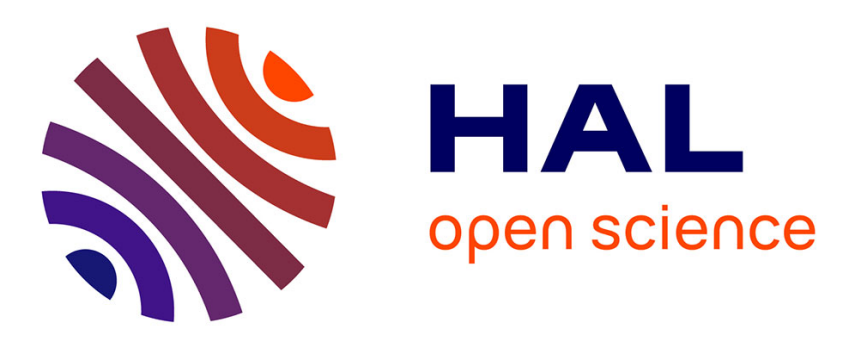

\title{
An Artificial Interface for High Cell Voltage Aqueous-Based Electrochemical Capacitors
}

Marco Olarte, Marie-Joëlle Menu, Patrice Simon, Marie Gressier, Pierre-Louis Taberna

\section{To cite this version:}

Marco Olarte, Marie-Joëlle Menu, Patrice Simon, Marie Gressier, Pierre-Louis Taberna. An Artificial Interface for High Cell Voltage Aqueous-Based Electrochemical Capacitors. Journal of The Electrochemical Society, 2021, 168 (7), pp.070520. 10.1149/1945-7111/ac10f5 . hal-03371278

\section{HAL Id: hal-03371278 \\ https://hal.science/hal-03371278}

Submitted on 8 Oct 2021

HAL is a multi-disciplinary open access archive for the deposit and dissemination of scientific research documents, whether they are published or not. The documents may come from teaching and research institutions in France or abroad, or from public or private research centers.
L'archive ouverte pluridisciplinaire $\mathbf{H A L}$, est destinée au dépôt et à la diffusion de documents scientifiques de niveau recherche, publiés ou non, émanant des établissements d'enseignement et de recherche français ou étrangers, des laboratoires publics ou privés. 


\section{OATAO \\ Open Archive Toulouse Archive Ouverte}

\section{Open Archive Toulouse Archive Ouverte (OATAO)}

OATAO is an open access repository that collects the work of Toulouse researchers and makes it freely available over the web where possible

This is a Publisher's version published in: http://oatao.univ-toulouse.fr/28154

Official URL: https://doi.org/10.1149/1945-7111/ac10f5

\section{To cite this version:}

Olarte, Marco Marie $\fallingdotseq$ and Taberna, Pierre-Louis An Artificial Interface for High Cell Voltage Aqueous-Based Electrochemical Capacitors. (2021) Journal of The Electrochemical Society (JES), 168 (7). 070520. ISSN 0013-4651

Any correspondence concerning this service should be sent to the repository administrator: tech-oatao@listes-diff.inp-toulouse.fr 


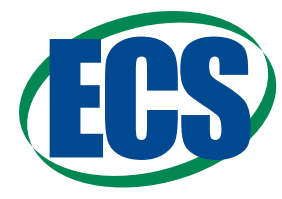

\title{
An Artificial Interface for High Cell Voltage Aqueous-Based Electrochemical Capacitors
}

\author{
Marco Olarte, ${ }^{1}$ (i) Marie-Joelle Menu, ${ }^{1}$ () Patrice Simon, ${ }^{1,2, *}$ (1) Marie Gressier, ${ }^{1}$ (i) and Pierre- \\ Louis Taberna ${ }^{1,2, z_{(1)}}$
}

${ }^{1}$ CIRIMAT, UMR CNRS 5085-Université Toulouse 3, 31062 Toulouse cedex 9, France

${ }^{2}$ Réseau sur le Stockage Electrochimique de l'Energie (RS2E), CNRS FR3459, Amiens 80039, France

\begin{abstract}
Aqueous electrolytes are very effective for supercapacitor applications but their narrow electrochemical potential window $(\sim 1 \mathrm{~V})$ and associated limited energy currently limits their use. Here, we demonstrate a new strategy to enlarge the potential window by designing an artificial interface (ai). An effective $a i$ was achieved via a mixture of siloxanes doped with an ionic liquid, 1-ethyl-3methylimidazolium bis(trifluoromethylsulfonyl)imide (EMI TFSI). Indeed, the as-deposited ai on the carbon-based electrode hinders the electron charge transfer but not the ionic charge transfer, making the $a i$ ionic conductive. As a result, a cell voltage of about $1.8 \mathrm{~V}$ was obtained in aqueous electrolyte-EMI $\mathrm{HSO}_{4} 1 \mathrm{~mol}^{-1}$ in water. Used as a membrane, the $a i$ was found to be ionically specific to $\mathrm{EMI}^{+}$; the proton transference number being close to zero. These results show the strategy of developing an $a i$ at the electrode/electrolyte interface could represent a new path for aqueous-based carbon-carbon supercapacitors to reach higher cell voltages, providing both higher specific energy and power.

(C) 2021 The Author(s). Published on behalf of The Electrochemical Society by IOP Publishing Limited. This is an open access article distributed under the terms of the Creative Commons Attribution 4.0 License (CC BY, http://creativecommons.org/licenses/ by/4.0/), which permits unrestricted reuse of the work in any medium, provided the original work is properly cited. [DOI: 10.1149/ 1945-7111/ac10f5]
\end{abstract}

Manuscript submitted April 9, 2021; revised manuscript received June 18, 2021. Published July 13, 2021. This paper 40, was presented during the 239th Meeting of the Electrochemical Society, May 30-June 3, 2021.

Supplementary material for this article is available online

The use of aqueous-based electrolytes in an electrochemical energy storage system (EES) is very attractive over organic-based systems, thanks to following key features: a lower cost, a lower toxicity, a higher safety level, and an easier recycle ability. ${ }^{1,2}$ However, despite the obvious advantages, the major flaw of aqueous-based electrolytes is the poor electrochemical stability, because water electrolysis leads to operating cell voltages to about $1 \mathrm{~V}$, although they usually achieve one order of magnitude higher conductivity than their organic counterpart. ${ }^{3-6}$ Consequently, the energy density $-E$, in $\mathrm{Wh} \mathrm{kg}^{-1}$-and the power density- $\mathrm{P}$, in $\mathrm{W} \mathrm{kg}^{-1}$ - are a cut below those of organic-based devices. ${ }^{7-9}$ As a matter of fact, these both metrics have a quadratic change with the cell voltage $\left(\mathrm{V}^{2}\right)$. This issue is most prominent in devices like Electrical Double-Layer Capacitors (EDLCs). ${ }^{10}$ Because these devices store energy via the adsorption of ions with no redox reactions, this gives them high power performance and long cycle life, but in turn makes them overly sensitive to the cell potential that can be applied to avoid side reactions limiting so its specific energy. 11,12

So far, a workaround for higher specific energy have been done, those last past years, to set up different strategies as a combination of a carbon electrode with a faradic electrode ${ }^{13-15}$ (battery electrode or pseudocapacitive) or through the development of new active materials, ${ }^{16-18}$ including the development of new electrolytes. ${ }^{9,19-22}$ Significant capacitance improvements have been reached from the active material side, ${ }^{23}$ some cell voltage enhancements have been obtained, thanks to the use of new electrolytes. ${ }^{5,24}$ Still, there is room for improvements: best cell voltages in diluted neutral aqueous electrolyte reported ${ }^{25,26}$ so far are below $1.6 \mathrm{~V}$, with a reasonable coulombic efficiency and cyclability.

Assuming the cell voltage is driven by the electrode/electrolyte charge transfer kinetic-carbon oxidation and electrolyte electroactivity-, another strategy deals with the surface modification/ functionalization of the electrodes. For this aspect, strategies based on an artificial solid electrolyte interface ( $a-S E I)$ concept, which aim at passivating the electrode/electrolyte interface-no more electron charge transfer-, but without affecting the ionic charge transfer: a

*Electrochemical Society Member.

${ }^{\mathrm{z}}$ E-mail: pierre-louis.taberna@univ-tlse3.fr higher voltage stability of the electrode should be expected. $a$-SEIs have already been envisaged but mainly for metal-anode battery chemistries $^{27-29}$ and in organic electrolytes ${ }^{30}$ to prevent the formation of dendrites. ${ }^{31,32}$ Other recent approaches have shown the use of a $a-S E I$ in aqueous electrolytes, but its aim was to suppress the electrolyte/electrode side reactions metal-ion batteries, ${ }^{33,34}$ without any significant operating voltage increase. But to the best of our knowledge, such kind of approach has not been yet applied to Electrochemical Double-Layer Capacitors (EDLC), which are nonfaradic systems. ${ }^{33,35}$

In this study, a strategy focused on the electrolyte/electrode interface, using a silicon and ionic liquid chemistry, ${ }^{36-39}$ is reported. We formed an artificial interface (ai) via a non-hydrolytic sol-gel route, by mixing the silica network precursors (tetramethoxysilane, TMOS and tetraethoxysilane, TEOS) with an organic-inorganic hybrid network precursor (dodecyltriethoxysilane, DTES). An ionic liquid (1-ethyl-3-methylimidazolium bis(trifluoromethylsulfonyl) imide, EMI TFSI) is added to the sol for obtain a hybrid siliconbased matrix ionically doped. An $a i$ is obtained after the deposition of the resultant sol on a carbon electrode. The bottom line is the $a i$ is an ionogel-like coating at the carbon surface. Thanks to the presence of this hydrophobic passivation ai layer, it is expected water molecules cannot access to the electrode surface, ${ }^{40-42}$ which is expected to participate to the enhancement of electrode voltage stability, while not hampering counterions flux, when the cell is polarized. ${ }^{31,43}$

\section{Experimental}

Reagents and standards.-Silicate precursors tetraethoxysilane (TEOS), tetramethoxysilane (TMOS) and dodecyltriethoxysilane (DTES) were obtained from Sigma Aldrich. 1-ethyl-3-methyl imidazolium bis(trifluoromethanesulfonylimide), EMI TFSI 99.9\% was purchased from Solvionic (Toulouse, France) and 1-ethyl-3methyl imidazolium hydrogen sulfate $\left(\mathrm{EMI} \mathrm{HSO}_{4}\right)$ were purchased from Sigma Aldrich, used without any further purification. Ethyl acetate (EthAc) purchased from Sigma Aldrich. Formic acid (FA), 98\% purchased from Arcos Organics. Glassy carbon substrates $25 \times$ $25 \mathrm{~mm}$ were obtained from Alfa Aesar. FMK30 activated carbon cloth (ACC) purchased from Chemviron was used as porous electrode. Whatman membrane $\mathrm{GF} / \mathrm{B}$ with a thickness of $0.8 \mathrm{~mm}$ was used as material for $a i$ supported membranes ( $a i$-SM). 
A plate material evaluating cell provided by Biologic was used to test the electrochemical stability of $a i$-GC (artificial interfacemodified glassy carbon). A magnetic mount electrochemical h-cell (Redox.me) was used to test the $a i$-SM. Swagelok cells were used to test porous carbon electrodes, where glassy carbon rods were used as current collectors.

Preparation of the ai sol.- -The ai sol was achieved by mixing the silicate precursors and the ionic liquid through a sol-gel process. As described in Figs. 1A and 1B, a non-hydrolytic sol-gel route, reported by Sharp, ${ }^{36}$ was used, consisting in a mixture of two alkoxysilanes (TEOS and TMOS), an organoalkoxysilane (DTES) and formic acid (FA) as a catalyst agent. Formic acid was mixed to three silica precursors under moderate stirring $(200 \mathrm{rpm})$, at room temperature, for $2 \mathrm{~h} 30 \mathrm{~min}$, to initiate sol-gel reactions. Then the sol was added to a solution of EMI TFSI (IL) in ethyl acetate (EthAc). EthAc was used to obtain a homogeneous mixture. The volume ratio TEOS:TMOS:DTES:FA:IL:EthAc was kept to 1:1:1.7:2.5:14.5:31. No maturation of the $a i$ sol was needed prior coating method.

Coating of the ai on the substrates.-Prior to the deposition of the ai sol, a piece of carbon cloth (FM30K, Chemviron UK) was ultrasonically cleaned with acetone, ethanol, and distilled water followed by drying in vacuum at $80{ }^{\circ} \mathrm{C}$ over a night. The Whatman membranes were used as received, without any pre-treatment. The coatings were then obtained by a dip-coating process. Thus, pretreated substrates were dipped vertically into the $a i$ sol, at $500 \mathrm{~mm} \mathrm{~min}^{-1}$, without any rest time and subsequently withdrawn at 10,50 or $600 \mathrm{~mm} \mathrm{~min}^{-1}$. The notation for the samples will be such that ai-ACC-withdrawal rate. For instance, ai-ACC-50 stands for a sample coated using a withdrawal speed of $50 \mathrm{~mm} \mathrm{~min}^{-1}$. Finally, the obtained ai coatings were placed in an oven for $12 \mathrm{~h}$ at $50{ }^{\circ} \mathrm{C}$ and then in a vacuum oven, during $60 \mathrm{~h}$ at $80{ }^{\circ} \mathrm{C}$, for removing sol-gel reaction by-products.

Characterizations and analyses.-Surface characterization.The scanning electron microscopy (SEM) VEGA3 from TESCAN
(Toulouse France) was used to investigate the morphology of the coating on electrodes with a $10 \mathrm{kV}$ operating voltage. Energy dispersive spectroscopy (EDS) from Oxford Instruments was used to determine the elemental composition. Drop Shape Analyzer DSA30E from KRÜSS Scientfic was used to analyze the hydrophobicity of samples. Droplets of $5 \mu \mathrm{l}$ deionized water drop was dropped carefully onto the samples and the final contact angle values were determining by averaging the data at five randomly selected position at ambient conditions. Fourier-transform infrared spectroscopy (FTIR), in conjunction with attenuated total reflection (ATR), was used to record infrared spectra in a Thermo Scientific Nicolet model 6700 FT-IR spectrometer between 4000 and $500 \mathrm{~cm}^{-1}$. Thermal gravimetric analysis (TGA) measurement was performed on a SETARAM TGA 92 92-16.18 (Caluire, France) via scanning a temperature range from 25 to $600{ }^{\circ} \mathrm{C}$ under nitrogen flow with a heating rate of $5^{\circ} \mathrm{C} \mathrm{min}^{-1}$.

Electrochemical measurements.-Potentiostat SP200 from BioLogic Science Instruments were used to characterize different electrochemical techniques. Linear sweep voltammetry (LSV) was carried out to determinate the electrochemical stability window at $1 \mathrm{mV} \mathrm{s}^{-1}$, using a plate glassy carbon (Bio-Logic) as working electrode; a platinum wire, as counter and $\mathrm{Ag} / \mathrm{AgCl}$ as reference electrode. Glassy carbon working electrodes were thoroughly cleaned ultrasonically in high purity alcohol, and then washed three times with distilled water and dried in ambient conditions before measurement.

Membrane potential was measured from the potential difference between a pair of $\mathrm{Ag} / \mathrm{AgCl}$ reference electrodes that were set in two different compartments separated by the membrane of interest (Fig. 2). The open circuit potential (OCP), from two reference electrodes immersed in $0.001 \mathrm{~mol} \mathrm{l}^{-1}$ and $1 \mathrm{~mol} \mathrm{l}^{-1}$, keeping a constant concentration gradient of 10 . The volume of reservoirs was $12 \mathrm{ml}$, and the diameter of membrane was $1 \mathrm{~cm}$. OCP was measured when steady state was reached from the higher to the lower concentrated reservoir.

A

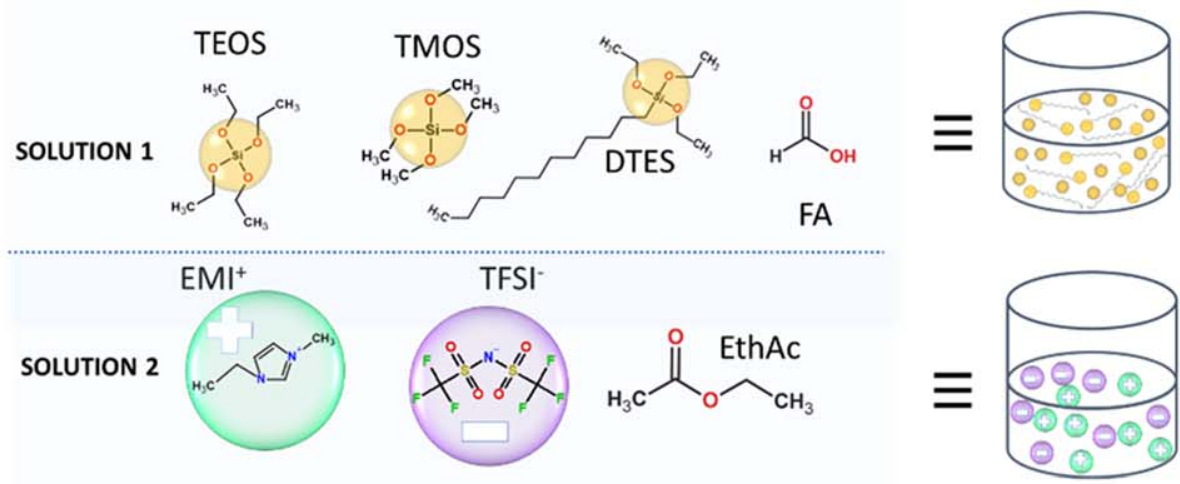

B

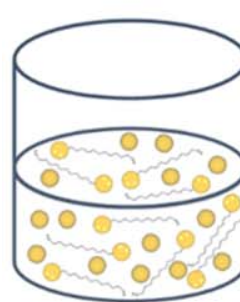

SOLUTION 1
SOLUTION 2

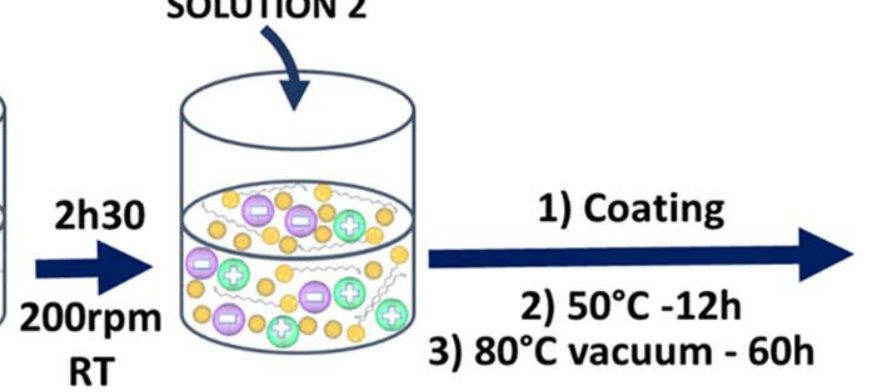

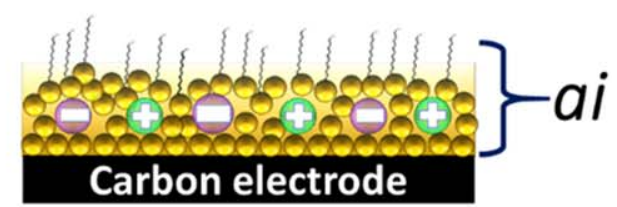

Carbon electrode

Figure 1. (A) Solution 1 with the siloxane mixture in formic acid and Solution 2 containing EMI TFSI in ethyl acetate. (B) Fabrication process of ai-coated electrodes by mixing solution $1+2$ then carbon electrodes are coated to form $a i$-coated electrodes after drying and aging. 


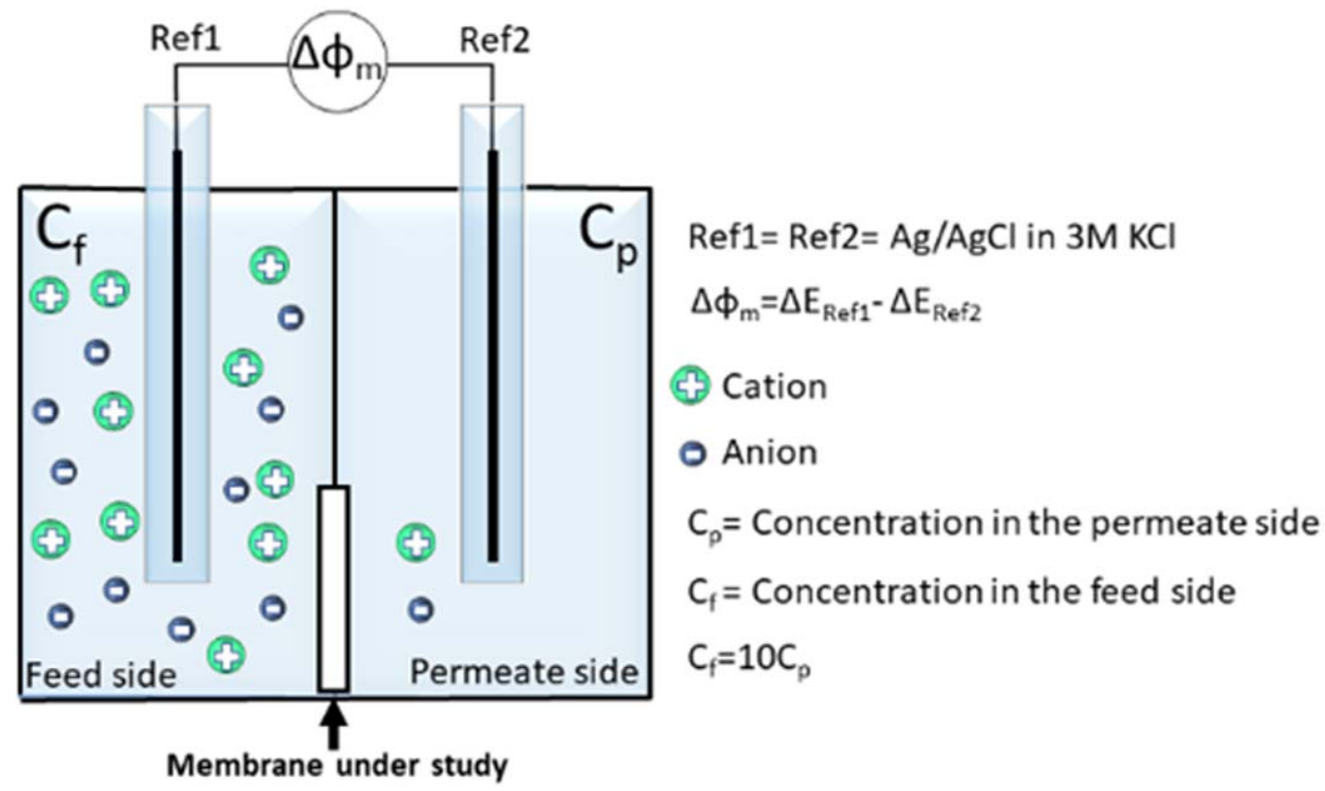

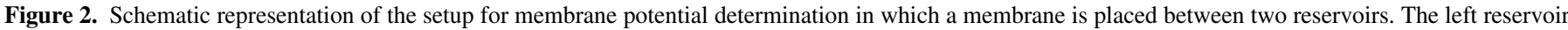

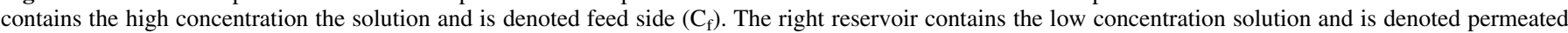
side $\left(C_{p}\right)$. The potential was measured from the left side to the right side. The ratio concentration is fixed to $C_{f}=10 C_{p}$.

Areal resistance of a membrane was determined by potential electrochemical impedance spectroscopy (PEIS) (Fig. S9 (available online at stacks.iop.org/JES/168/070520/mmedia)); applying a sinusoidal modulation of $5 \mathrm{mV}$, at a frequency of $1 \mathrm{kHz}$ between two platinum wired electrodes. The membrane potential was assessed from potential drop between the two $\mathrm{Ag} / \mathrm{AgCl}$ reference electrodes, dipped in each compartment filled, with $12 \mathrm{ml}$ of 0.001 to $0.05 \mathrm{~mol}^{-1}$ solution.

Electrochemical performance of coated porous electrodes was investigated using a conventional three-electrode configuration (half-cell) and a two-electrode symmetric configuration (full or single cell). All the measurements were performed at room temperature. The electrochemical cells were tested by cyclic voltammetry $(\mathrm{CV})$, galvanostatic cycling with potential limitation (GCPL), and electrochemical impedance spectroscopy (EIS). The testing was performed using computer controlled multichannel potentiostat/galvanostat Bio-Logic VMP3, driven by EC-Lab v10.40 software. The CV tests were conducted at $5 \mathrm{mV} \mathrm{s}^{-1}$. EIS measurements were carried out within a frequency range of $100 \mathrm{kHz}$ down to $5 \mathrm{mHz}$, at an open circuit voltage, with a RMS AC voltage amplitude of $5 \mathrm{mV}$. Stability test were performed by constant voltage-holding (floating) experiments, where a cell voltage of $1.8 \mathrm{~V}$ was applied for $2.50 \mathrm{~h}$, then 5 cycles in galvanostatic cycling (chronopotentiometry) were recorded. The discharge capacitance value of the last cycle recorded was plotted vs time. This process was repeated until a loss of $20 \%$ of the initial capacitance was reached.

Membrane potential background.-To investigate the ionic selectivity of the artificial interface as a supported membrane, as depicted in Fig. 2, we measured the potential difference across the membrane generated between two reservoirs, the permeate side at low relative concentration $\left(C_{p}\right)$ and the feed side at high relative concentration $\left(C_{f}\right)$; i.e., $C_{f}>C_{p}$. If the membrane is $100 \%$ selective to a particular ion $\mathrm{i}$, the membrane potential $\left(\Delta E_{m}\right)$ related to the theoretical Nernst potential, i.e. $\Delta E_{m}=\Delta E_{\text {Nernst }}=\frac{R T}{z_{i} F} \ln \left(\frac{C_{f}}{C_{p}}\right)$.

Nevertheless, charged membranes being far from ideal behaviour, ${ }^{44,45}$ the model used to characterize the diffusivity of ions through the artificial interface as a supported membrane is derived from the Nernst-Plank equations via the theory TeorellMeyer-Sievers (TMS), proposed by Teorell, Meyer and Sievers, ${ }^{46,47}$ which describes the equilibrium potentials across a membrane splitting two reservoirs at different electrolyte concentrations, depending on different anion and cation diffusivities. We used a modified model derived from Lefebvre et al., ${ }^{48}$ as shown in Eq. 1 the dimensionless membrane potential, in which the equilibrium potential is made up of two main contributions: the Donnan potential $\left(\Delta E_{\text {Donnan }}\right)$, accounting for the inter-diffusion region between the membrane and the electrolyte; the diffusion potential due to the concentration gradient $\left(\Delta E_{D i f f}\right)$. Furthermore, as reported by Ghosh et al., we added the $\alpha$ parameter before the Donnan contribution from non-idealities. ${ }^{49}$

$$
\begin{aligned}
& \Delta \phi_{m}=\alpha \Delta E_{\text {Donnan }}+\Delta E_{\text {Diff }}=\alpha \frac{1}{z_{2}} \ln \left(\frac{k_{2}^{p}}{k_{2}^{f}}\right) \\
& +\left(\frac{t_{2}}{\left|z_{2}\right|}-\frac{t_{1}}{\left|z_{1}\right|}\right) \ln \left(\frac{K_{r} k_{2}^{p}+t_{1} \zeta_{f}}{k_{2}^{f}+t_{1} \zeta_{f}}\right)
\end{aligned}
$$

Where, $\Delta \phi_{m}=\frac{F \Delta E_{m}}{R T} ; t_{1}=\frac{\left|z_{1}\right| u_{1}}{\left|z_{1}\right| u_{1}+\left|z_{2}\right| u_{2}} ; t_{2}=\frac{\left|z_{2}\right| u_{2}}{\left|z_{1}\right| u_{1}+\left|z_{2}\right| u_{2}}$; $\zeta_{f}=\frac{C_{m}}{\left|z_{1}\right| \nu_{1} C_{f}}, K_{r}=\frac{C_{p}}{C_{f}}$.

$\Delta \phi_{m}$ is the dimensionless TMS potential, $E_{m}$ is the experimental membrane potential $(\mathrm{V}), \mathrm{R}$ is the gas constant $\left(\mathrm{J} \mathrm{mol}^{-1} \mathrm{~K}^{-1}\right), \mathrm{T}$ is the absolute temperature (K), $\mathrm{F}$ is Faraday's constant $\left(\mathrm{C} \mathrm{mol}^{-1}\right), K_{r}$ is a transmission coefficient, which denotes the ability of solute to pass through the membrane. $\alpha$ is a dimensionless parameter accounting for a Debye length correction factor due to the membrane geometry; ${ }^{49} k_{2}^{p}$ and $k_{2}^{f}$ are the partition coefficients of ion between the permeate and the feed side of the membrane, respectively; these coefficients are related to external concentration as described furthermore in detail in Fig. S1. $t_{1}$ and $t_{2}$ are the transference numbers of the cation and the anion, respectively; $u_{1}$ and $u_{2}$ are the ionic mobilities in the membrane of the cation and the anion $\left(\mathrm{m}^{2} \mathrm{~s}^{-1}\right)$, respectively; $z_{1}$ and $z_{2}$ are the electrochemical valence of the cation and the anion, respectively. $\nu_{i}$ is the stoichiometric coefficient of electrolyte, $C_{m}$ is the charge concentration in the 
membrane $\left(\mathrm{mol} \mathrm{m}^{-3}\right)$ related to the pore volume in the membrane, $\zeta_{f}$ the ratio of the volume charge density to equivalent salt concentration in the feed side.

Thus, as showed in Fig. S2, three domains are present according to the concentration of the solutions in each reservoir, with respect to $C_{m}$. At extremely low ionic concentrations, the fixed charged concentration is larger than the electrolyte concentration i.e., $C_{f} C_{m}{ }^{-1} \ll 1$; in this regime, the potential reaches a plateau ascribed to the Donnan exclusion of co-ions; the potential will only depend on $\alpha$ as described in Eq. 2.

$$
\Delta \phi_{m}\left(C_{f} C_{m}^{-1} \ll 1\right) \approx \alpha \Delta E_{\text {donnan }} \approx \alpha\left[\frac{R T}{z_{2} F} \ln \left(\frac{C_{f}}{C_{p}}\right)\right]
$$

At higher ionic concentrations i.e., $C_{f} C_{m}{ }^{-1} \gg 1$; no more ionic exclusion occurs leading a plateau only depending on the transference number of the different involved ions as described in Eq. 3. For $t_{1}=1$, better mobility for cations and oppositely for $t_{1}=0$.

$$
\Delta \phi_{m}\left(C_{f} C_{m}{ }^{-1} \gg 1\right) \approx \Delta E_{D i f f} \approx\left(\frac{t_{2}}{\left|z_{2}\right|}-\frac{t_{1}}{\left|z_{1}\right|}\right) \frac{R T}{F} \ln \left(\frac{C_{f}}{C_{p}}\right)
$$

Between these two situations, for the intermediate concentrations, neither the Donnan exclusion, nor the diffusion prevails. So, from the membrane potential with $C_{f}$, the different diffusion coefficient ratios through the $a i$-membrane have been assessed for different type of electrolytes: EMI $\mathrm{HSO}_{4}$ and $\mathrm{H}_{2} \mathrm{SO}_{4}$. Concerning 1-2 electrolytes, Eq. 1 was used to fit experimental data (Fig. 5A). The constant volume charge density of charged membrane ( $\mathrm{mol} \mathrm{l}^{-1}$ of pore volume) $\left(C_{m}\right)$, the dimensionless correction factor $\alpha$ from non-idealities in the membrane, and the $t_{1}$ value corresponding to cation transference number in the membrane re the only parameters to fit.

\section{Results and Discussion}

Chemical and microstructural characterizations.-SEM images were realized in secondary electron mode (Figs. 3A and 3B) and in backscattered electron mode (Fig. S3). As observed, the ai-ACC (Fig. 3B) exhibits an even ai deposit, as compared to the ACC sample (Fig. 3A). Besides, water droplet contact angle measurements were performed exhibiting a drastically different value: $0^{\circ}$ for ACC (Fig. 3A, inset), $136^{\circ}$ for $a i$-ACC (Fig. 3B, inset). This is consistent with a lower wettability of the activated carbon cloth after being covered with the $a i$, which shows the ACC becomes hydrophobic after being coated. From EDS analysis (Fig. S4), strong signals of $\mathrm{Si}, \mathrm{F}, \mathrm{S}, \mathrm{N}, \mathrm{O}$ elements can be observed, in line with presence of the $a i$ at the surface of the $a i$-ACC. The detection of a small quantity of $\mathrm{Al}$ is likely due to a contamination from the aluminum package where the electrodes were stored.

The chemical composition of the ai formed on the dip coated electrode were further analyzed by Fourier Transform Infrared spectroscopy (FTIR). The whole spectra are shown in Fig. S5. The absorption bands of the functional groups corresponding to the neat IL, $a i$-ACC-free-IL and the $a i$-ACC are compared. FTIR spectra shows the negligeable contribution in the IR spectra of the ACC substrate, while we can see clearly the presence of the absorption bands related to IL for $a i$-ACC, which confirms its presence inside the $a i{ }^{50,51}$ However, most of the bands associated with the Si-O-Si are dominated by IL peaks into ai-ACC sample, particularly some corresponding to the anti-symmetrical stretching vibration of Si-O$\mathrm{Si}$ bonds located around $1090 \mathrm{~cm}^{-1} .52$ As depicted in Fig. 3C the $2800-3200 \mathrm{~cm}^{-1}$ region spectra can nevertheless be analyzed, where the $\mathrm{C}-\mathrm{H}$ stretching vibrations of the dodecyl group from DTES $\left(2923 \mathrm{~cm}^{-1} \text { for }-\mathrm{CH}_{2}\right)^{53}$ and the imidazolium from IL $\left(3160 \mathrm{~cm}^{-1}\right.$ for $-\mathrm{CH}$ ) can be seen. Moreover, given the energy of the $-\mathrm{CH}_{2}$ stretching vibration which is closer from that of a liquid alkane $\left(2924 \mathrm{~cm}^{-1}\right)$ than that of the crystalline alkane $\left(2915-2918 \mathrm{~cm}^{-1}\right)$, it can be assumed that the dodecyl moieties of the sample are in a disordered state. ${ }^{54}$ In addition, the comparison of ai-ACC spectrum with the superposition of neat IL and $a i$-ACC-free-IL spectra shows neither new peaks nor peak shift were observed, indicating the absence of interaction between the ionic liquid and the hybrid matrix. This suggest that the imidazolium ring does not interact chemically with the dodecyl fragments but only physically. ${ }^{55}$

In Fig. 3D is shown thermogravimetric analyses of the $a i$-ACCfree-IL, the $a i$-ACC, and the neat IL. As a reference, the thermogravimetric behavior was also performed for the substrate ACC sample, which, as it can be observed, exhibits only a slight weight loss, ascribed to some water desorption and functional group release (Fig. S6). On the other hand, for $a i$-ACC sample, a sharp drop of weight is measured beyond $350{ }^{\circ} \mathrm{C}$, alike the neat IL. ${ }^{56}$ Thus, the confined IL have the same thermal stability than the neat IL: IL confinement has not changed the thermal properties, even with the addition of dodecyl moieties from DTES. ${ }^{37}$ This observation is consistent with FTIR measurement showing no interactions between the IL and the hybrid matrix. Moreover, by subtracting the residual weight at $550{ }^{\circ} \mathrm{C}$ from neat IL and $\mathrm{ACC}$, we can estimate the proportion of hybrid matrix present in the $a i$-ACC. Thus, the hybrid matrix content is about $39 \%$ in weight, which is in accordance with the value of $35 \%$, from the initial precursor weight.

Electrochemical characterizations.-Figure 4A shows the linear scanning voltammetry (LSV) on a bare glassy carbon electrode compared to artificial interface-modified glassy carbon (ai-GC), tested in aqueous electrolyte $1 \mathrm{~mol}^{-1} \mathrm{EMI} \mathrm{HSO}_{4}$, at $1 \mathrm{mV} \mathrm{s}^{-1}$. As observed, the overall stability voltage window has been increased because of both cathodic and anodic overpotentials are higher: oxygen - at the anode-and hydrogen-at the cathode-evolution potentials occur beyond the thermodynamic stability limits of water, which leads to a voltage window higher $3.6 \mathrm{~V}$. Furthermore, $1 \mathrm{mmol} \mathrm{l}^{-1}$ of $\left.\mathrm{Fe}(\mathrm{CN})_{6}\right]^{3-} /\left[\mathrm{Fe}(\mathrm{CN})_{6}\right]^{4-}$ was added into the electrolyte as a reversible redox mediator to evidence any charge transfer across the electrode/electrolyte interface, for both the $b$-GC and the $a i$-GC. As observed in Fig. 4B, the electrochemical signature is drastically different for $b$-GC and $a i$-GC, since an expected oxidation and reduction peaks are present for $b$-GC, oppositely to $a i-\mathrm{GC}$ : no electron transfer occurs for $a i-\mathrm{GC}$, the electrode is passivated. Figure $4 \mathrm{C}$ illustrates the ai-concept for a passivated layer but ionic conductive.

Interestingly, a lower electrode impedance is measured for ai-GC in presence of $\mathrm{EMI}^{+}$cation (Fig. S7, comparing ai-GC impedance in $\mathrm{H}_{2} \mathrm{SO}_{4}$ and EMI $\mathrm{HSO}_{4}$ ). At a first sight, it can be assumed a better ionic conduction through the membrane for $\mathrm{EMI}^{+}$cation than for $\mathrm{H}^{+}$. Nevertheless, this point has to be refined and further analyses have been performed the get a better understanding of the transport mechanism across the electrode/electrolyte interface.

Transport properties of the ai as a supported membrane.Results presented in Fig. S7 suggested an ion selectivity of the $a i$ in favor of $\mathrm{EMI}^{+}$. To go further in the analysis, the ai layer was deposited onto a glass fiber Whatman membrane to obtain a standalone $a i$ membrane to be tested in the cell configuration presented in Fig. 2. The membrane-supported ai layer ( $a i-\mathrm{SM})$ was thus placed between a two-compartment cell, each compartment containing different electrolyte concentrations. A constant concentration gradient of 10 was maintained while testing different concentrations for the feed side $\left(C_{f}\right)$ and the permeate side $\left(C_{p}\right)$, it to say $C_{f}=10 C_{p}$. The open circuit voltage (OCV) of the cell was measured for each concentration between $C_{p}$ and $C_{f}$. A 2-probe cell configuration used allows for estimating the potential drop across the $a i-\mathrm{SM}$ as being the OCV of the cell. The Teorell-Meyer-Sievers (TMS) model was used to describe the variation of the membrane potential with the electrolyte concentration. ${ }^{47,57-59}$ The overall potential in TMS theory, which can be derived from the 
A
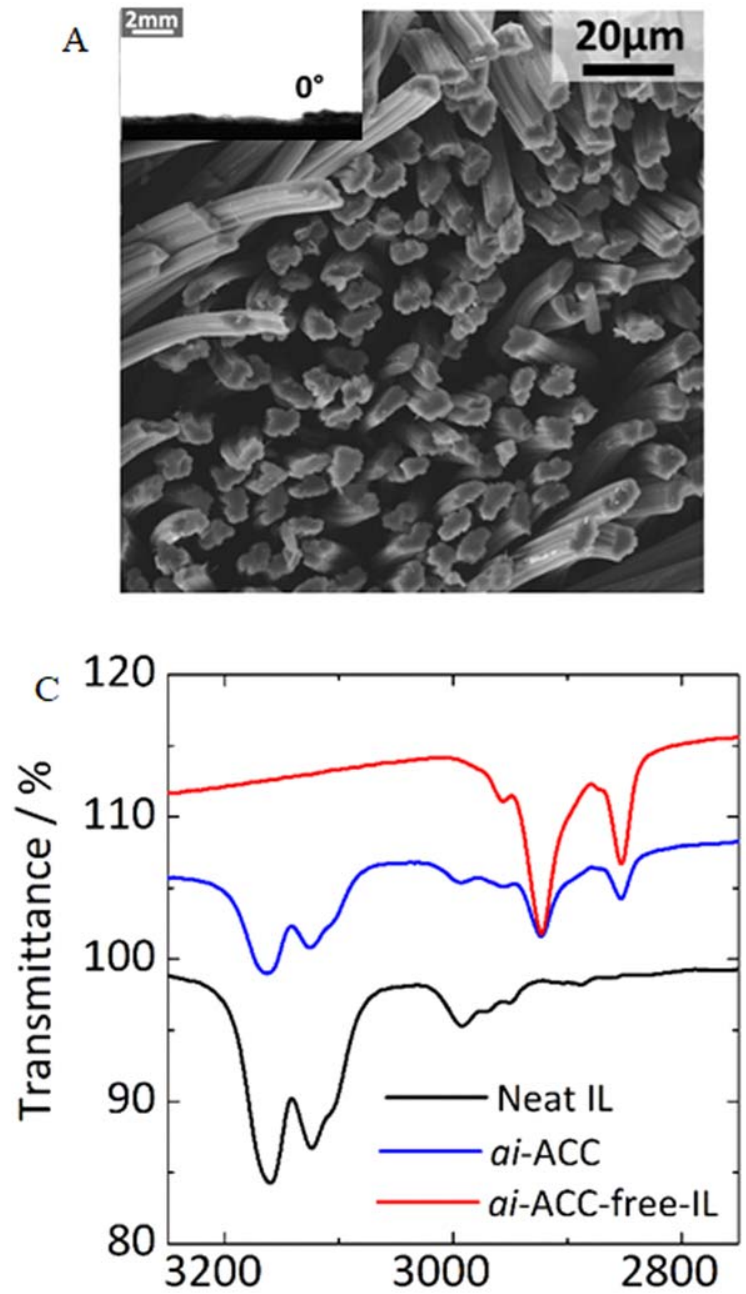

Wavenumber $/ \mathrm{cm}^{-1}$
B
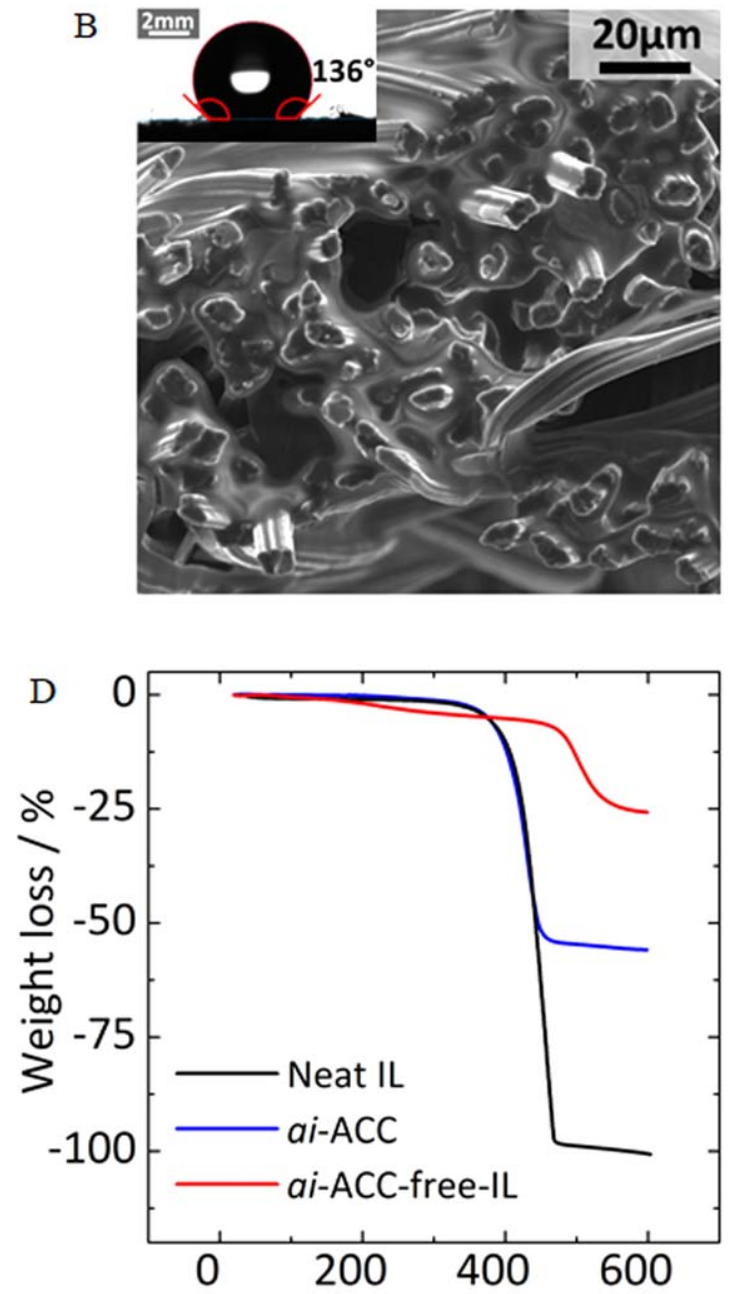

Temperature $/{ }^{\circ} \mathrm{C}$

Figure 3. (A) SEM images of activated carbon cloth (ACC) and (B) for the ai dip coated on ACC (ai-ACC) showing a homogeneous coating with no evident macroporosity. The insets display the wettability of the carbon cloth electrodes A the photograph of a water droplet on the ACC spreading and permeating quickly on the fabric; (B) the photograph of a water droplet on the $a i$-ACC with a contact angle of $136^{\circ}$ (C) IR spectra of the $a i$-ACC (blue), neat IL (black) and $a i$-ACC-free-IL (Red), showing the presence of dodecyl groups as well as that of the alkyls of the aromatic ring of the EMI ${ }^{+}$cation without shifting the peaks, which implies that the cations do not interact chemically but physically with the dodecyl chain. (D) TGA thermograms of ACC (red), ai-ACC (blue) and neat IL (black).

Nernst-Planck equations, as shown above is given by the modified TMS model. ${ }^{49}$

Figure 5A compares the membrane potentials obtained for

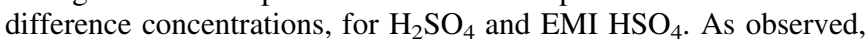
oppositely to $\mathrm{EMI} \mathrm{HSO}_{4}$ at $\mathrm{pH}=7$, there is no correlation between the membrane potential and the $\mathrm{H}_{2} \mathrm{SO}_{4}$ concentration-same was observed with $\mathrm{K}_{2} \mathrm{SO}_{4}$ at $\mathrm{pH}=7$ (Fig. S8). On the other hand, the membrane potential change with EMI $\mathrm{HSO}_{4}$ exhibits a trend in line with the TMS model for 1:2 electrolytes (Fig. S1) - in Fig. S9 is presented the correlation plot between the actual values and the predicted ones obtained from the model. Such finding is consistent with a membrane selectivity: only $\mathrm{EMI}^{+}$can access the ai-SM. Going further, from the fitting parameters, it was found firstly a value of $C_{m}$ of $12.4 \mathrm{mmol}^{-1}$ i.e., the $a i$-SM is a weakly charged membrane which confirms the validity of the model because in our case the TMS model does not overestimate the membrane potential. ${ }^{59}$ The non-ideality factor $\alpha$ is close to 0.37 showing low exclusion of co-ions ${ }^{60}$ and furthermore $t_{1}=1$ which confirms a higher $\mathrm{EMI}^{+}$mobility through the membrane than $\mathrm{SO}_{4}{ }^{2-}$. Based on the understanding provided above, Figure $5 \mathrm{~B}$ illustrates the improved ion transport of $\mathrm{EMI}^{+}$through the ai-SM membrane.
The membrane conductivity was also determined by impedance measurement in the 4 electrodes configuration (Fig. S10), in which the contribution of the resistance of the membrane and solution was calculated by applying a $5 \mathrm{mV}$ sinusoidal amplitude from $100 \mathrm{kHz}$ to $1 \mathrm{kHz} .{ }^{61}$ The measured conductances are presented in Fig. $5 \mathrm{C}$, as a function of the cation concentration. As reported from Galama et al. ${ }^{62}$ a series model was assumed for the determination of the membrane conductance. Therefore, the total conductance of the cell was expressed with two terms: one depending on the feed electrolyte solution $\left(G_{S}\right.$, in $\left.\mathrm{S}\right)$ and one on the membrane conductance $\left(G_{m}\right.$, in $\left.\mathrm{S}\right)$.

$$
\mathrm{G}_{T}=\frac{\mathrm{G}_{m} \mathrm{G}_{s}}{\mathrm{G}_{m}+\mathrm{G}_{s} \mathrm{k}_{C}}
$$

Where $k_{C}$ is the dimensionless concentration, obtained by dividing the concentration in each reservoir $(C)$ with the reference concentration, $C_{0}=1 \mathrm{~mol} \mathrm{l}^{-1}$. For this experiment the same cell configuration as before (Fig. S10) was used but with $C_{f}=C_{p}$. From the fitting, $G_{m}$ was obtained. Considering the geometry of the membrane, we found a value for the membrane conductivity $\left(\sigma_{m}\right)$

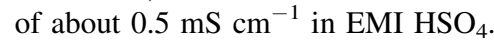


A

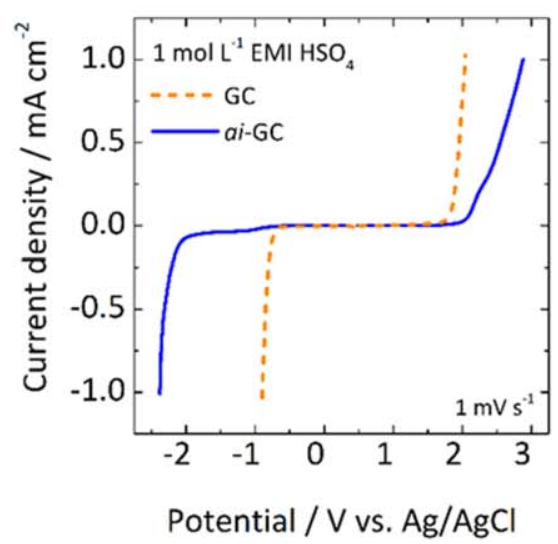

B

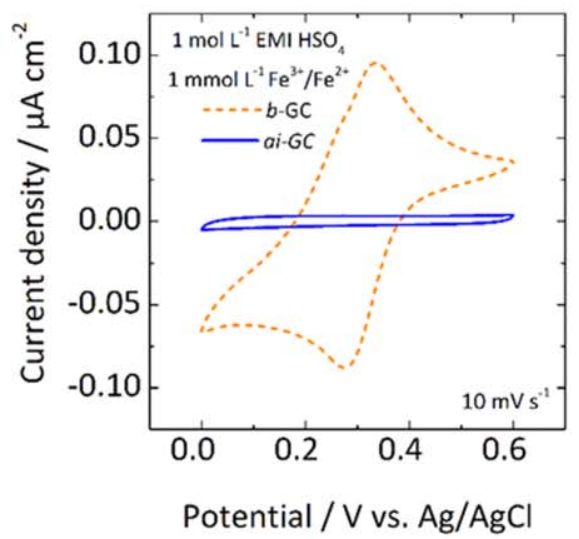

$\mathrm{C}$

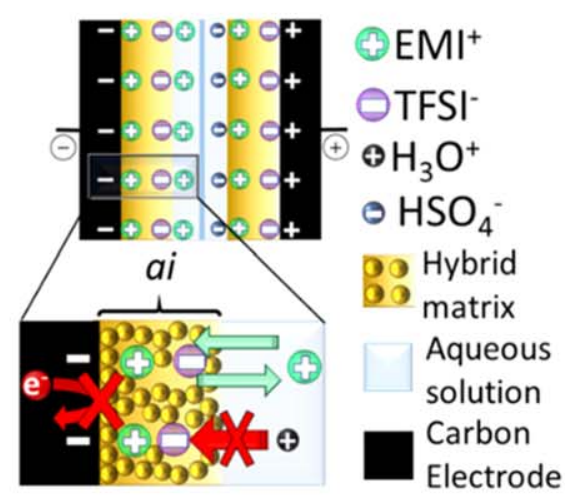

Figure 4. (A) Electrochemical stability window of the ai drop-casted on glassy carbon (GC) electrode in $1 \mathrm{~mol} \mathrm{~L}^{-1}$ EMI HSO4. Measurements were taken with linear sweep voltammetry (LSV) on glassy carbon working electrodes at $1 \mathrm{mV} \mathrm{s}^{-1}$ (B) Electrode passivation highlighted with a redox probe in solution. Comparison of CVs obtained with a pristine glassy carbon and ai drop-casted GC electrode. (C) Schematic of the ai as a coated layer on carbon electrodes in a supercapacitor device in which the ai coating helps to passivate the electrode surface but with $\mathrm{EMI}^{+}$conduction through the electrodes.

A

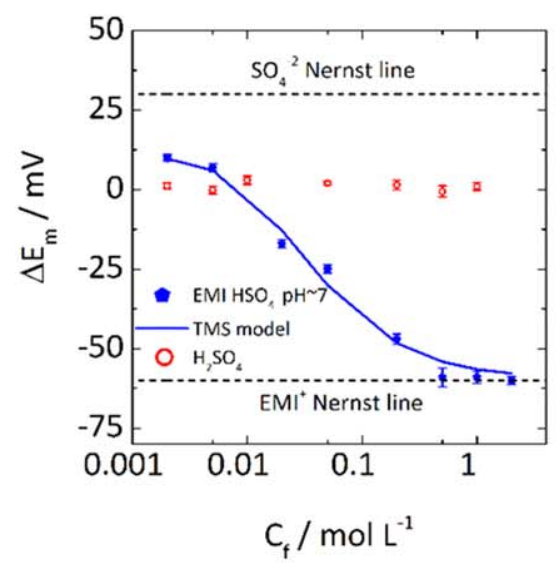

B

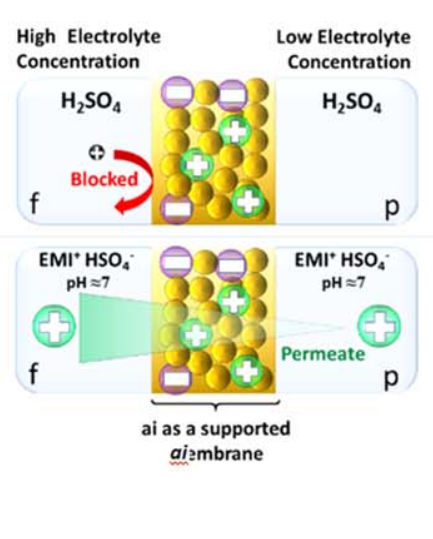

$\mathrm{C}$

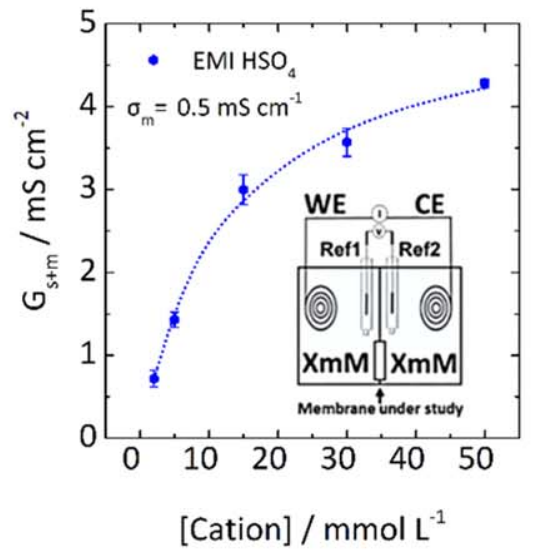

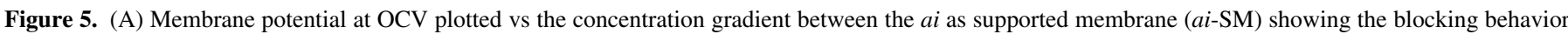

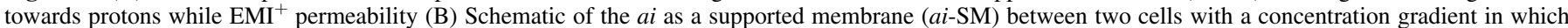

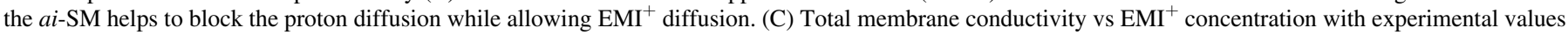
fitted with the model of serial conductance.

Overall, the proposed study shed some light on the transport properties of ai coating, which was considered as an ionic membrane. It was possible to study ion mobility through the layer as well as its affinity to different ions. Therefore, the $a i$-SM behaves as cationic membrane and turns out to be selective with respect to $\mathrm{EMI}^{+}$cations.

Porous carbon and supercapacitor device.-Withdrawal speed and transport properties.-The potential of using the ai coating on a porous carbon as electrode for a supercapacitor was subsequently evaluated. For this purpose, activated carbon cloth (ACC) was used as an active material on which an ai layer was deposited via dipcoating. So, in a first place, the withdrawal speed has been optimized by studying the impedance responses of the ai dip-coated activated carbon cloth ( $a i$-ACC) based electrodes. The $a i$-ACC was used as a working electrode, an ACC serving as the counter electrode, an $\mathrm{Ag} / \mathrm{AgCl}$ electrode as the reference electrode, with $1 \mathrm{~mol}^{-1}$ EMI $\mathrm{HSO}_{4}$ aqueous solution, as the electrolyte.

Nyquist plots (Fig. S11), for ACC electrode, and for freshly prepared $a i$-ACC electrodes are presented for different withdrawal speeds. As observed, three main regions can be considered: ${ }^{63}$ one at high frequency, corresponding the bulk electrolyte resistance; another in the mid-range frequency linked to ionic properties of the porous carbon electrode; the low frequencyregion corresponding the capacitive behavior of the electrode, as expected for an activated carbon. Compared to ACC, it can be found at low frequencies, for $a i$-ACC samples, a nearly linear curve and the value of the $-Z_{\mathrm{im}}$ still in the same order of magnitude indicating a capacitive behavior with similar performances than ACC. Regarding the mid-range frequency region, a closer look allows to observe a R-C loop, ascribed to the $a i$, and $45^{\circ}$ region corresponding to the ion transport throughout the ACC, slowed down by the presence of the ai. From the Nyquist plot, we extracted the variation of the imaginary part of the capacitance $\left(C^{\prime \prime}\right)$ as a function of the real part of the impedance $\left(Z_{r}\right)$, which, as demonstrated in a previous publication, ${ }^{64}$ present a way to measure quantitatively the different resistive part of interest: ionic resistance of the $a i\left(\mathrm{R}_{a i}\right)$ and the ion resistance of the electrode $\left(\mathrm{R}_{\text {ion in pore }}\right)$. In Fig. 6A is presented the variation of those two resistances as a function of the withdrawal speed. By assuming a negligeable contribution of the ai to capacitance, the $\mathrm{R}_{a i}$ can be deduced from the $\mathrm{Z}_{\mathrm{r}}$ shift of the ai-ACC samples by comparing it to that of the ACC electrode directly on the graph. Regarding the $\mathrm{R}_{\mathrm{ion}}$ in pore, values were obtained from the $Z_{r}$ values at the start of the steep increase in $\mathrm{C}^{\prime \prime}$ to its maxima. 
A

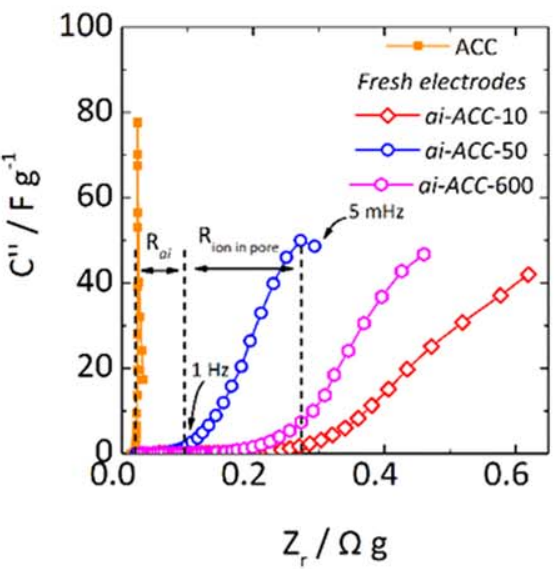

B

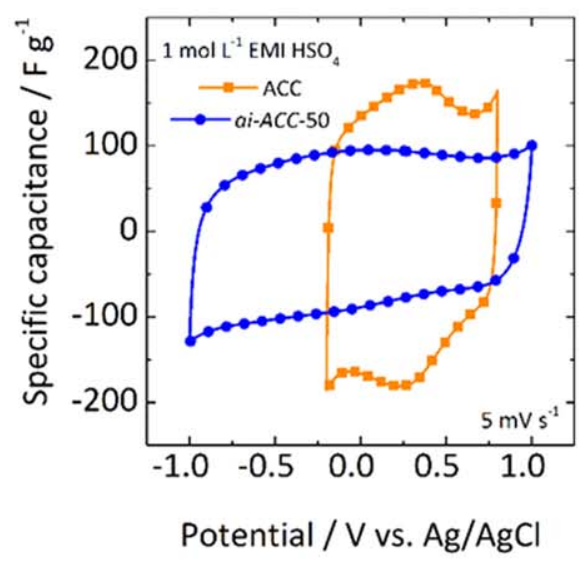

$\mathrm{C}$

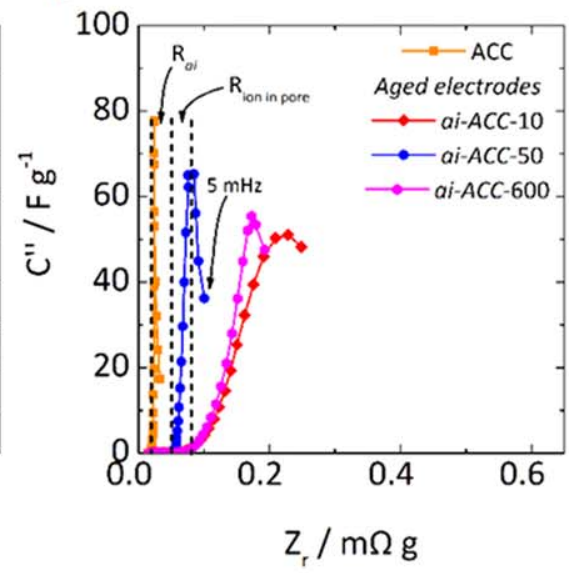

$\mathrm{D}$

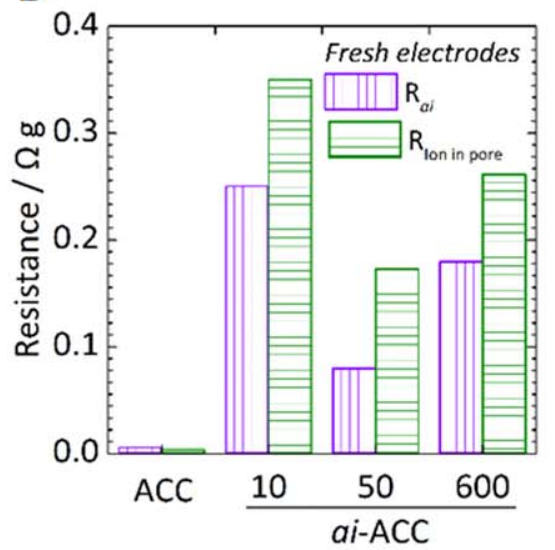

E

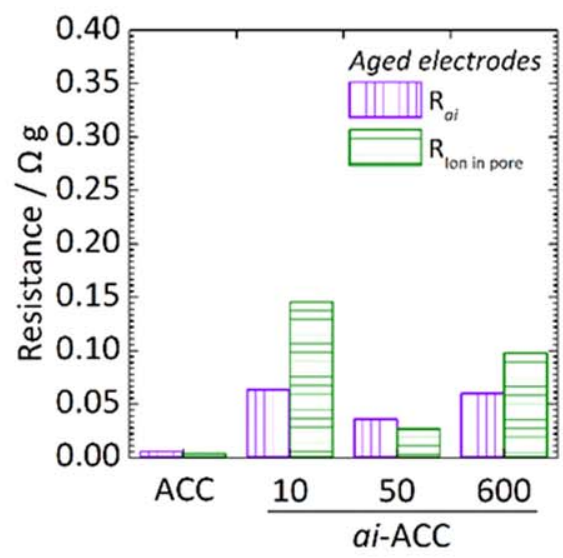

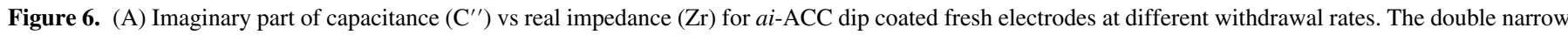

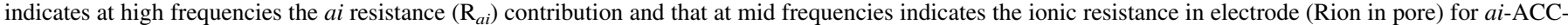

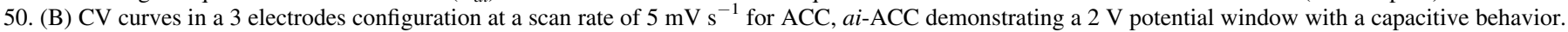

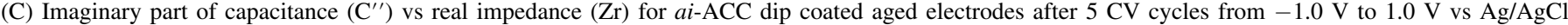

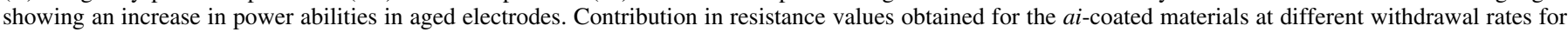
fresh prepared in (D) and aged in (E).

The $\mathrm{C}^{\prime \prime}$ vs $\mathrm{Z}_{\mathrm{r}}$ plots at different withdrawal speeds in Fig. 6A show a clear difference between ACC and freshly ai-ACC electrodes. ACC displays a curve with an expected behavior in porous carbons ${ }^{64}$ with $\mathrm{C}^{\prime \prime}$ close to 0 at high frequencies then at mid frequencies a steep increase in $\mathrm{C}^{\prime \prime}$ at low resistance (close to $20 \mathrm{~m} \Omega \mathrm{g}$ ), with a clear maximum at $77 \mathrm{Fg}^{-1}$ and then rapidly decreasing along the $x$ axis at low frequencies. For $a i$-ACC electrodes, $\mathrm{C}^{\prime \prime}$ remains close to 0 at higher $\mathrm{Z}_{\mathrm{r}}$ values than those compared to ACC, suggesting the presence of a passivated layer on the electrode, i.e., the ai dip coated layer. The calculated $\mathrm{Z}_{\mathrm{r}}$ shift in Fig. $4 \mathrm{C}$ show higher $\mathrm{R}_{a i}$ values at extremely low and high withdrawal rates close to 250 and $180 \mathrm{~m} \Omega \mathrm{g}$, for $a i$-ACC-10 and $a i$-ACC-600, respectively, compared to $80 \mathrm{~m} \Omega \mathrm{g}$ for $a i$-ACC-50.

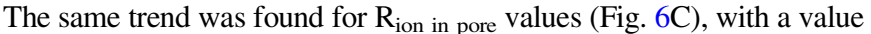
close to $0.004 \Omega \mathrm{g}$ for ACC, and a value of $0.17 \Omega \mathrm{g}, 1.40 \Omega \mathrm{g}$ and $1.04 \Omega \mathrm{g}$, respectively $a i$-ACC-50, $a i$-ACC-10 and $a i$-ACC-600. Besides, a maximum in $\mathrm{C}^{\prime \prime}$ at $50 \mathrm{~F} \mathrm{~g}^{-1}$ was found for ai-ACC-50 whereas not maximum was found for the other samples, in line with a lower limitation of ion transport inside the porous electrode. ${ }^{65}$ From the SEM images of $a i$-ACC at different withdrawal rate (Fig. S12), it can be observed thicker coatings and with high weight loadings at extreme rates, which is consistent with the higher resistance measured for those samples. Oppositely to dip-coating performed on smooth surface, dip-coating on ACC does not follow the expected LandauLevich law, which predict a thickness increase with the withdrawal speed. But our results are in line with the literature, showing that the final thickness of a sol-gel-based coating in porous materials is linked to the process. ${ }^{66}$ It is worth noting a log-log thickness evolution vs withdrawal speed has been reported for high withdrawal speed $\left(600 \mathrm{~mm} \mathrm{~min}^{-1}\right)$, leading to higher deposit thickness, oppositely to what is expected under Landau-Levich regime, whereas at lower rate the Landau-Levich applies. Nevertheless, for porous surface, a capillary regime is highly likely to take over, resulting in thicker films. ${ }^{66}$ Thus, assuming the density of the $a i$ independent to the thickness, the coating weight can be related to the ai thickness. In this way the results suggest a more important thickness at lower as well as at faster withdrawals rates, as reported in the literature. Importantly, resistance values obtained for the ai coated material, with the thinner dip coated layer (ai-ACC-50), leads to higher ionic conduction.

A further study was made by comparing the ACC and ai-ACC-50 with an $a i$-coated electrode free of ionic liquid during dip coating step (ai-ACC-free-IL). In Fig S13 one can see from the bode plot, comparing the three samples, a three orders of magnitude larger impedance response at low frequencies. As observed the high frequency region is also several order in magnitude higher than the $a i$-ACC including IL, which confirms the passivating effect of the ai. These results are completed, by plotting $\mathrm{C}^{\prime \prime}$ vs $\mathrm{Z}_{\mathrm{r}}$ in Fig. S14 in which the three samples are additionally compared. As discussed previously, $\mathrm{C}^{\prime \prime}$ remains close to 0 at extremely high $\mathrm{Z}_{\mathrm{r}}$ values than those compared to ACC, $\mathrm{R}_{a i}$ value for $a i$-ACC-free-IL is close to $2 \Omega \mathrm{g}$, three orders of magnitude larger than ACC confirming the highly passivating effect of 
A

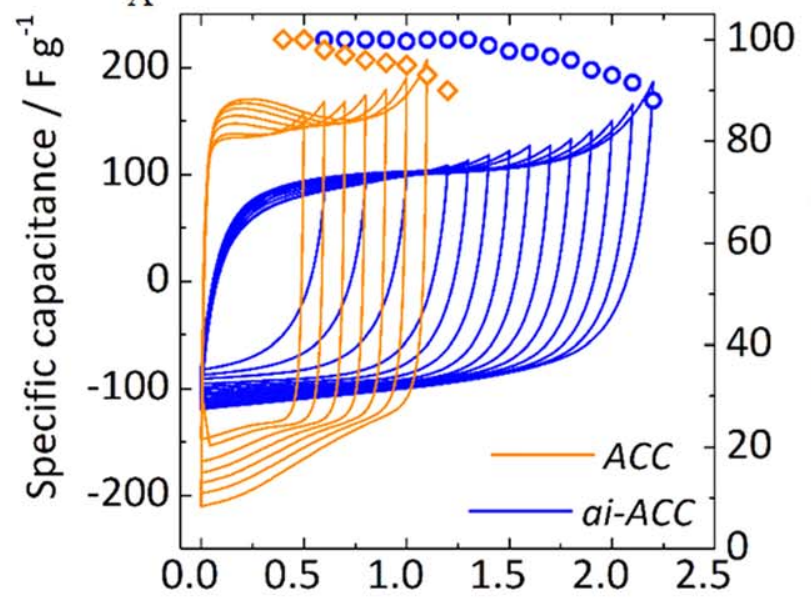

Cell Potential / V

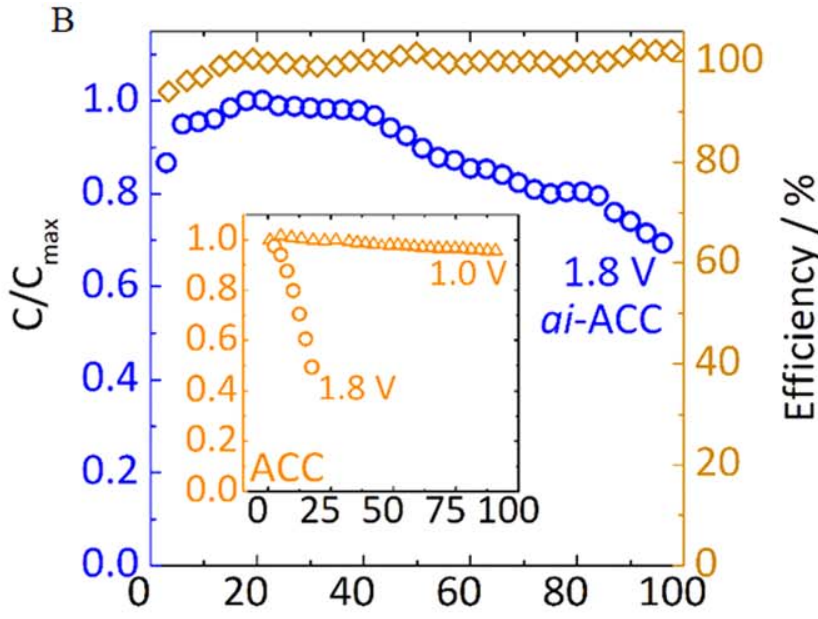

Time / h

Figure 7. (A) CV curves of symmetrical supercapacitors with ACC and ai-ACC electrodes showing the increase in voltage. The specific capacitance was normalized with respect to the weight of active material. The second $y$ axis plots the coulombic efficiency for each cycle at given voltage, the maximum charging voltage is retained for a coulombic efficiency of 95\%. (B) Floating test for $a i$-ACC by applying $1.8 \mathrm{~V}$ during $2 \mathrm{~h} 30$ and recording the capacitance retention after each cycle show the good stability at high potentials. The inset in B shows the recording capacitance retention in floating test for ACC electrodes which shows a stable behavior at $1 \mathrm{~V}$ and a high loss in capacitance retention at $1.8 \mathrm{~V}$.

the $a i$. Moreover, $\mathrm{R}_{\mathrm{ion}}$ in pore value is close to $6 \Omega \mathrm{g}$ for $a i$-ACC-free-IL vs $0.004 \Omega \mathrm{g}$ for ACC and shows a continuous plateau with no transition peak and exceptionally low $\mathrm{C}^{\prime \prime}$. As a result, the cyclic voltammogram achieved at $5 \mathrm{mV} \mathrm{s}^{-1}$ (Fig. S15) shows current response for ai-ACC-free-IL far lower than the other electrodes in Fig. $6 \mathrm{~B}$, because of the electrode passivation: without IL embedded in the silicon matrix, ionic transfer is highly hindered. ${ }^{33}$

The $a i$-ACC-50 electrode $\mathrm{CV}$ response and ACC electrode present a capacitive shape (Fig. 6B), both with a current in the same range of magnitude: the ai does not degrade de the overall ACC capacitance. Nevertheless, in the cathodic region, differently from ACC, thanks to the presence of the $a i$, the hydrogen evolution overpotential is extended from $-0.20 \mathrm{~V}$ vs ref, for ACC electrode, to $-1.0 \mathrm{~V}$ vs ref, for $a i$-ACC electrodes. During anodic polarization, the potential limit was increased from $0.8 \mathrm{~V}$ to $1.0 \mathrm{~V}$ vs ref, because of the existence of an overpotential for oxygen evolution. These results are consistent with the LSV experiments on ai-GC electrodes, discussed above in Fig. 4A, where the major contribution of the $a i$ was observed on the negative side likely due to a poor proton transport through the $a i$, as demonstrated above.

The EIS analysis after CV is Nyquist plot for aged ai-ACC electrodes after CV tests are shown in Fig S16, we can see a highly decrease in the mid frequency region from the $45^{\circ}$ region corresponding to the ion transport throughout the ACC, compared to freshly ones in Fig. S10 suggesting an improvement in ionic transfer for all the samples tested. This was confirmed by plotting C' $v s Z_{r}$ in Fig. $4 C$; we can see clearly that the shift in $Z_{r}$ is lower than for fresh ones, thus, as showed in Fig. $4 \mathrm{D}$, lower $\mathrm{R}_{a i}$ values for all the samples are found. However, it still between 6 to 12 times higher than ACC. Moreover, the $\mathrm{R}_{\mathrm{ion}}$ in pore value for $a \mathrm{i}$-ACC-50 is $0.02 \Omega \mathrm{g}$, i.e., 6 times higher than ACC. As a result, as shown in Fig. S17, ai-ACC50 shows a relative lower capacitance retention at higher scan rates compared to ACC, however the capacitance retention is still very decent-not to mention the enhancement of the electrochemical voltage window that the ai brings. Electrochemical analysis clearly indicates the originality of the ai-concept to achieve higher cell voltage aqueous-based supercapacitor.

Electrochemical capacitor device and stability.-The electrochemical performance of ai-ACC based symmetric EDLC device in $1 \mathrm{~mol} \mathrm{l}^{-1} \mathrm{EMI} \mathrm{HSO}_{4}$ is shown in Fig. 7A. First, CV measurement was performed for a symmetric ai-ACC-50: $a i$-ACC-50 device at $5 \mathrm{mV} \mathrm{s}^{-1}$. The cell voltage was increased by $0.1 \mathrm{~V}$ step to track the coulombic efficiency evolution. The maximum charging voltage defined here as the cell voltage obtained with a coulombic efficiency of $95 \%$, was measured at $1.8 \mathrm{~V}$. This represents a dramatic cell voltage increase of $0.8 \mathrm{~V}$ compared to a ACC-ACC symmetric

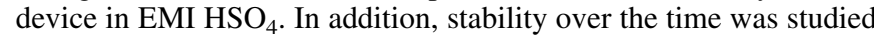
by a floating. The normalized capacitance, which relates to the maximum capacitance reached $\left(\mathrm{C} / \mathrm{C}_{\max }\right)$, was calculated-its change vs time is presented in Fig. 7B. As noticed, for ACC electrode-based cell, for a moderate maximum cell voltage of $1 \mathrm{~V}$, as expected, a good stability over the time with a low decrease in normalized capacitance of $4 \%$ after $100 \mathrm{~h}$. But for a cell voltage of $1.8 \mathrm{~V}$, the $a i$-free, ACC electrode-based cell normalized capacitance dramatically fades. Concerning $a i$-ACC based symmetric supercapacitor, different regimes were found over the time: the first consisting of an increase in $\mathrm{C} / \mathrm{C}_{\max }$ after few polarization cycles: such "activation" step is assumed to promote the ionic transport through the $a i$ and to properly impregnate the porous carbon electrode, in line with the decrease of the in-pore ionic resistance (Fig. 6E). A plateau was further reached after $15 \mathrm{~h}$, corresponding to the maximum cell capacitance. The capacitance is kept up steady for more than $60 \mathrm{~h}$, until it decays gradually. Anyway, a capacity loss of $20 \%$ was reached after $100 \mathrm{~h}$. The origin of this degradation is still under investigation, but this improvement is however promising: the working cell voltage has been almost doubled, since it is close to $2 \mathrm{~V}$, resulting in a 4-time energy improvement. The development of an $a i$ at the surface of a carbon electrode represents an interesting strategy, since it makes possible to reach higher cell voltages using low cost, low toxicity and safe $\mathrm{H}_{2} \mathrm{SO}_{4}$ aqueous-based electrolytes, which are known to achieve higher carbon capacitances thanks to higher ionic conductivity. $6,9,67$

\section{Conclusions}

In this work, we succeeded in preparing a high voltage supercapacitor operating in aqueous electrolyte by tailoring the carbon electrode/electrolyte interface. We developed a passive layer, termed as artificial interface (ai), which avoids electronic transfer but allows for ionic conduction; as a result, the ion absorption/desorption process needed to form the electrochemical double layer can be achieved. The $a i$ is composed by a hybrid matrix, in which an ionic 
liquid is encapsulated by sol gel reactions. The presence of highly hydrophobic group such as dodecyl in this ai made it possible to improve the electrochemical stability of the $a i$ with respect to water, and this was achieved without sacrificing the ionic conductivity of the interface. The ionic transport properties of the $a i$ were further studied by designing a supported membrane. Results showed a proton-blocking behavior of the interface, the conductivity being selectively achieved by $\mathrm{EMI}^{+}$cations. Our $a i$ was then deposited onto porous carbon cloth electrodes by dip-coating technique, and supercapacitor cells were assembled. A cell voltage close to $2.0 \mathrm{~V}$

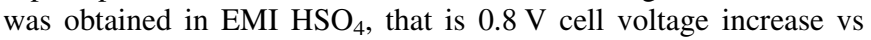
non-modified carbon electrodes. This strategy is really promising, and further works have now to be devoted to find out a trade-off between the electrode passivation and ion transport across the $a i$, by optimizing the thickness and the formulation of that ai. Anyhow, the set of results presented here evidences the opportunities offered by the $a i$-layer concept in view of increasing aqueous-based supercapacitors cell voltage, which is still the bottleneck that limits their development.

\section{Acknowledgments}

We gratefully acknowledge funding by Paul Sabatier University and the Minister of Higher Education, Research and Innovation (MESRI) for its financial support.

\section{ORCID}

Marco Olarte (iD https://orcid.org/0000-0002-9289-0922

Marie-Joelle Menu (iD https://orcid.org/0000-0001-6295-0739

Patrice Simon (iD https://orcid.org/0000-0002-0461-8268

Marie Gressier (D) https://orcid.org/0000-0002-3773-7773

Pierre-Louis Taberna (iD https://orcid.org/0000-0002-5310-0481

\section{References}

1. W. Guo, C. Yu, S. Li, Z. Wang, J. Yu, H. Huang, and J. Qiu, Nano Energy, 57, 459 (2019)

2. Q. Gou, S. Zhao, J. Wang, M. Li, and J. Xue, Nano-Micro Lett., 12, 1 (2020).

3. X. Zhang, X. Wang, L. Jiang, H. Wu, C. Wu, and J. Su, J. of Power Sources, 216, 290 (2012).

4. D. R. MacFarlane, N. Tachikawa, M. Forsyth, J. M. Pringle, P. C. Howlett, G. D. Elliott, and C. A. Angell, Energy Environ. Sci., 7, 232 (2014).

5. D. Xiao, Q. Wu, X. Liu, Q. Dou, L. Liu, B. Yang, and H. Yu, ChemElectroChem, 6, 439 (2019)

6. H. E. Darling, J. Chem. Eng. Data, 9, 421 (1964).

7. A. Lewandowski, A. Olejniczak, M. Galinski, and I. Stepniak, J. Power Sources, 195, 5814 (2010)

8. M. Yu, Y. Lu, H. Zheng, and X. Lu, Chem.-A Eur. J., 24, 3639 (2018).

9. B. Pal, Yang, R. S, T. V, and J. R, Nanoscale Adv., 1, 3807 (2019).

10. P. Díaz, Z. González, R. Santamaría, M. Granda, R. Menéndez, and C. Blanco, Electrochim. Acta, 168, 277 (2015).

11. Z. Weng, F. Li, D. W. Wang, L. Wen, and H. M. Cheng, Angew. Chemie-Int. Ed., 52, 3722 (2013).

12. H. Shao, Y. C. Wu, Z. Lin, P. L. Taberna, and P. Simon, Chem. Soc. Rev., 49, 3005 (2020).

13. K. Fic, M. Meller, and E. Frackowiak, J. Electrochem. Soc., 162, A5140 (2015).

14. M. Nakayama, S. Osae, K. Kaneshige, K. Komine, and H. Abe, J. Electrochem Soc., 163, A2340 (2016)

15. K. Chiang, N.,. S. Zhang, and G. Z. Chen, ECS Trans., 16, 153 (2008).

16. W. Zuo, C. Xie, P. Xu, Y. Li, and J. Liu, Adv. Mater., 29, 1 (2017).

17. X. Shan, D. S. Charles, Y. Lei, R. Qiao, G. Wang, W. Yang, M. Feygenson, D. Su, and X Teng, Nat. Commun., 7, 1 (2016).

18. Y. Shao, M. F. El-Kady, J. Sun, Y. Li, Q. Zhang, M. Zhu, H. Wang, B. Dunn, and R. B Kaner, Chem. Rev., 118, 9233 (2018).

19. L. Suo, O. Borodin, T. Gao, M. Olguin, J. Ho, X. Fan, C. Luo, C. Wang, and K. Xu, Science, 350, 938 (2015).

20. P. Lannelongue, R. Bouchal, E. Mourad, C. Bodin, M. Olarte, S. Le Vot, F. Favier, and O. Fontaine, J. Electrochem. Soc., 165, A657 (2018).
21. D. Reber, R.-S. Kühnel, and C. Battaglia, Sustain. Energy Fuels, 1, 2155 (2017).

22. J. Xie, Z. Liang, and Y. C. Lu, Nat. Mater., 19, 1006 (2020).

23. L. Yu, L. Hu, B. Anasori, Y. T. Liu, Q. Zhu, P. Zhang, Y. Gogotsi, and B. Xu, ACS Energy Lett., 3, 1597 (2018).

24. S. Thareja and A. Kumar, ACS Sustain. Chem. Eng., 9, 2338 (2021).

25. L. Demarconnay, E. Raymundo-Piñero, and F. Béguin, Electrochem. Commun., 12 1275 (2010).

26. K. Fic, G. Lota, M. Meller, and E. Frackowiak, Energy Environ. Sci., 5, 5842 (2012).

27. Q. Zhao, M. J. Zachman, W. I. Al Sadat, J. Zheng, L. F. Kourkoutis, and L. Archer, Sci. Adv., 4, 1 (2018).

28. N. W. Li, Y. X. Yin, C. P. Yang, and Y. G. Guo, Adv. Mater., 28, 1853 (2016).

29. S. G. Patnaik, T. P. Jayakumar, Y. Sawamura, and N. Matsumi, ACS Appl. Energy Mater., 4, 2241 (2021).

30. B. Han, A. R. Dunlop, S. E. Trask, B. Key, J. T. Vaughey, and F. Dogan J. Electrochem. Soc., 165, A3275 (2018).

31. S. Wei, S. Choudhury, J. Xu, P. Nath, Z. Tu, and L. A. Archer, Adv. Mater., 29, 1605512 (2017).

32. X. B. Cheng, C. Yan, X. Chen, C. Guan, J. Q. Huang, H. J. Peng, R. Zhang, S. T. Yang, and Q. Zhang, Chem, 2, 258 (2017).

33. J. Zhi, A. Zehtab Yazdi, G. Valappil, J. Haime, and P. Chen, Sci. Adv., 3, e1701010 (2017).

34. S. Jeong, B. H. Kim, Y. D. Park, C. Y. Lee, J. Mun, and A. Tron, Journal of Alloys and Compounds, 784, 720 (2019).

35. B. E. Conway, Proc. Int. Power Sources Symp., 138, 319 (1991).

36. K. G. Sharp, J. Sol-Gel Sci. Technol., 2, 35 (1994).

37. M. A. Néouze, J. Le Bideau, P. Gaveau, S. Bellayer, and A. Vioux, Chem. Mater., 18, 3931 (2006).

38. L. Nègre, B. Daffos, P. Taberna, and P. Simon, J. Electrochem. Soc., 162, A5037 (2015).

39. L. Nègre, B. Daffos, V. Turq, P. L. Taberna, and P. Simon, Electrochim. Acta, 206 490 (2016)

40. Q. Yang, Z. Zhang, X. G. Sun, Y. S. Hu, H. Xing, and S. Dai, Chem. Soc. Rev., 47, 2020 (2018)

41. R. Verma, N. Tomar, S. E. Creager, and D. W. Smith, Polymer (Guildf)., 53, 2211 (2012).

42. Y. A. Budkov, A. L. Kolesnikov, Z. A. H. Goodwin, M. G. Kiselev, and A. A. Kornyshev, Electrochim. Acta, 284, 346 (2018).

43. M. D. Tikekar, L. A. Archer, and D. L. Koch, Sci. Adv., 2, e1600320 (2016),

44. J. Cervera, V. García-Morales, and J. Pellicer, J. Phys. Chem. B, 107, 8300 (2003).

45. Y. Lanteri, A. Szymczyk, and P. Fievet, Langmuir, 24, 7955 (2008).

46. K. H. Meyer and J.-F. Sievers, Helvetica Chimica Acta, 19, 649 (1913).

47. A. H. Galama, J. W. Post, H. V. M. Hamelers, V. V. Nikonenko, and P. M. Biesheuvel, J. Membr. Sci. Res., 2, 128 (2016).

48. X. Lefebvre, J. Palmeri, and P. David, J. Phys. Chem. B, 108, 16811 (2004).

49. M. Ghosh, K. F. A. Jorissen, J. A. Wood, and R. G. H. Lammertink, J. Phys. Chem. Lett., 9, 6339 (2018).

50. V. H. Paschoal, L. F. O. Faria, and M. C. C. Ribeiro, Chem. Rev., 117, 7053 (2017)

51. J.-C. Lassègues, J. Grondin, D. Cavagnat, and P. Johansson, J. Phys. Chem. A, 113, 6419 (2009).

52. P. J. Launer, Silicone Compd. Regist. Rev., 100, 175 (1987)

53. Z. H. Zhang, H. J. Wang, Y. H. Liang, X. J. Li, L. Q. Ren, Z. Q. Cui, and C. Luo, Sci. Rep., 8, 1 (2018)

54. S. Marcinko and A. Y. Fadeev, Langmuir, 20, 2270 (2004).

55. D. S. Ashby, R. H. DeBlock, C. H. Lai, C. S. Choi, and B. S. Dunn, Joule, 1, 344 (2017)

56. R. Hagiwara and Y. Ito, J. Fluor. Chem., 105, 221 (2000).

57. G. J. Hills, P. W. M. Jacobs, and N. Lakshminarayanaiah, Proc. R. Soc. London. Ser. A. Math. Phys. Sci., 262, 246 (1961).

58. X. L. Wang, T. Tsuru, S. ichi Nakao, and S. Kimura, J. Memb. Sci., 103, 117 (1995).

59. W. J. Shang, X. L. Wang, and Y. X. Yu, J. Memb. Sci., 285, 362 (2006).

60. M. Ghosh, L. Madauß, M. Schleberger, H. Lebius, A. Benyagoub, J. A. Wood, and R. G. Lammertink, Langmuir, 55, 7400 (2020).

61. P. Długołęcki, P. Ogonowski, S. J. Metz, M. Saakes, K. Nijmeijer, and M. Wessling, J. Memb. Sci., 349, 369 (2010).

62. A. H. Galama, D. A. Vermaas, J. Veerman, M. Saakes, H. H. M. Rijnaarts, J. W. Post, and K. Nijmeijer, J. Memb. Sci., 467, 279 (2014).

63. C. Portet, P. L. Taberna, P. Simon, and C. Laberty-Robert, Electrochim. Acta, 49, 905 (2004).

64. H. Banda, S. Périé, B. Daffos, L. Dubois, O. Crosnier, P. Simon, P. L. Taberna, and F. Duclairoir, Electrochim. Acta, 296, 882 (2019).

65. P. L. Taberna, P. Simon, and J. F. Fauvarque, J. Electrochem. Soc., 150, A292 (2003).

66. X. Tang and X. Yan, J. Sol-Gel Sci. Technol., 81, 378 (2017)

67. G. E. Walrafen, W. H. Yang, Y. C. Chu, and M. S. Hokmabadi, J. Solution Chem., 29, 905 (2000). 